\title{
WFUMB 2019 hosted by the Australasian Society for Ultrasound in Medicine (ASUM)
}

Time is ticking down to the premier multidisciplinary ultrasound conference of 2019.

WFUMB2019 will be held 6 - 9 September at the Melbourne Convention and Exhibition Centre in the state of Victoria, Australia.

This conference will offer cutting edge talks and workshops by world luminaries and local talent across a multitude of streams, including musculoskeletal, rheumatology, abdominal, gastrointestinal, paediatrics, emergency, critical care, breast, head \& neck, cardiac, obstetrics \& gynaecology, vascular, therapies and men's health. In addition, we shall be offering two days of ground-breaking medical education that will be suitable for all those involved in training.

September is the beginning of springtime in Australia and Melbourne is renowned for its social scene with tantalising restaurants, great coffee, art galleries and further afield to the scenic landscapes of Australia from the great Ocean Road to the vineyards of Mornington Peninsula, the Yarra Valley and Macedon Ranges. The conference centre is within easy walking distance to major hotels, great shopping arcades and beautiful gardens.

Abstracts for oral and poster presentations can now be submitted on line and conference registrations open 3 rd December 2018. Go to www.wfumb2019.org for more details.

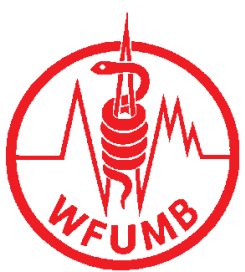

\section{The 17th World Federation for Ultrasound in Medicine and Biology Congress}

hosted by the Australasian Society for Ultrasound in Medicine

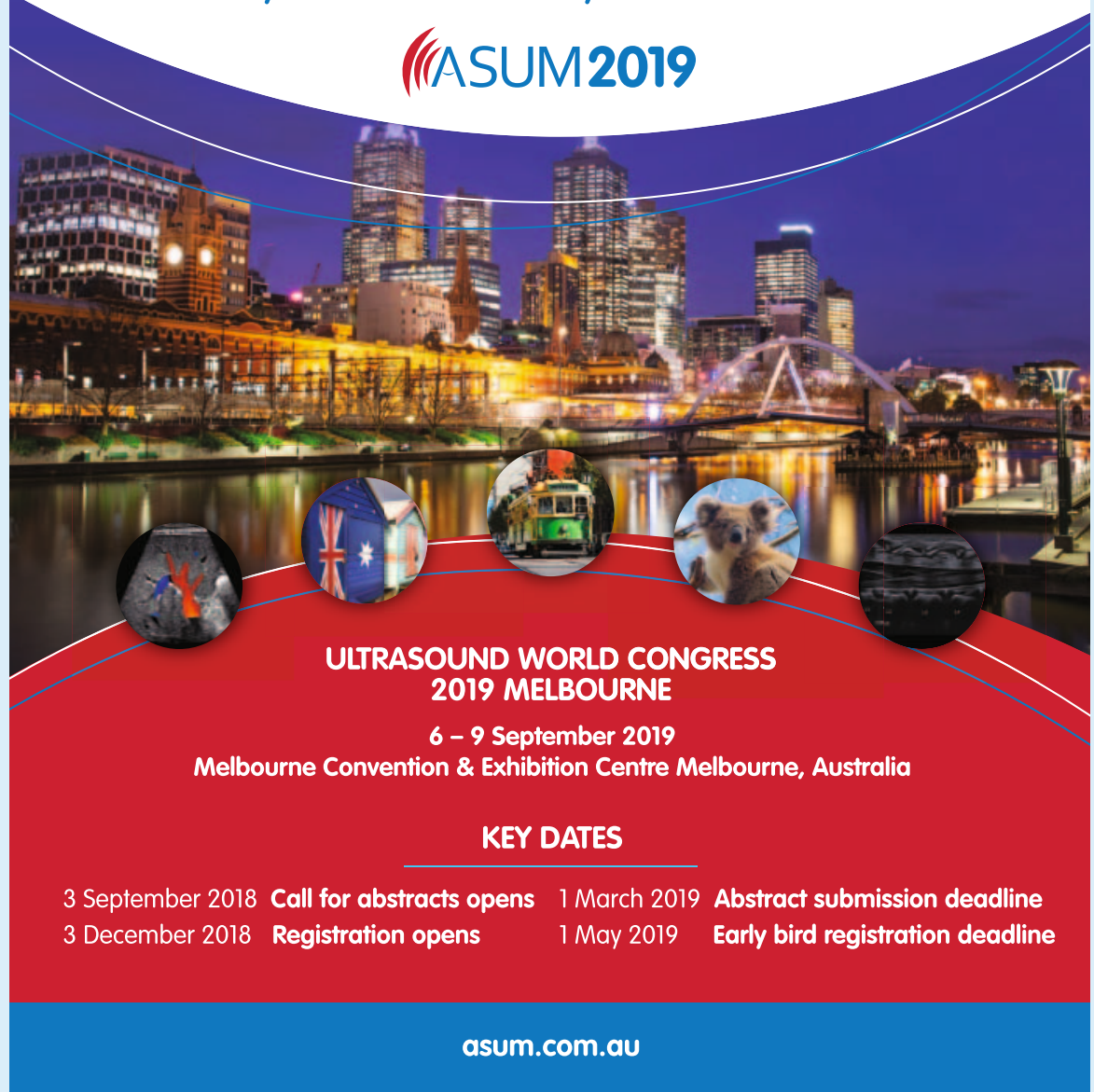

